\title{
The nature and strength of social motivations in young farmed silver fox vixens (Vulpes vulpes)
}

\author{
Anne Lene Hovland ${ }^{\mathrm{a}, *}$, Georgia J. Mason ${ }^{\mathrm{b}}$, \\ Richard D. Kirkden ${ }^{\mathrm{c}}$, Morten Bakken ${ }^{\mathrm{a}}$ \\ ${ }^{a}$ Norwegian University of Life Sciences, Department of Animal and Aquacultural Sciences, \\ P.O. Box 5003, N-1432 As, Norway \\ ${ }^{\mathrm{b}}$ Department of Animal and Poultry Science, University of Guelph, Guelph, Ontario, Canada N1G 2W1 \\ ${ }^{\mathrm{c}}$ Faculty of Land and Food Systems, University of British Columbia, 2357 Main Mall, \\ Vancouver, BC, Canada V6T $1 Z 4$
}

Accepted 20 June 2007

\begin{abstract}
To investigate the strength of social motivation and the motives underlying social contact in farmed silver foxes (Vulpes vulpes), we housed six young vixens continuously in a closed economy operant apparatus and measured their 'maximum price paid' when required to perform a task to obtain unrestricted social contact or food (a 'yardstick' resource). In the former trials, vixens of the same-age and origin acted as stimulus animals $(N=6)$, and both test and stimulus foxes could decide their own visit durations to a shared compartment. Their motives for visiting this 'social compartment' were examined by recording their behaviour during social contact. When access was almost free (a baseline fixed ratio schedule of 1 ) the test vixens visited the stimulus fox $30.3 \pm 4.3$ times and spent $45 \%$ of the time together per $24 \mathrm{~h}$. The stimulus foxes spent on average $80 \%$ per $24 \mathrm{~h}$ in the shared compartment and visited this cage $40.7 \pm 9.6$ times per $24 \mathrm{~h}$. When higher costs were imposed, the test vixens proved willing to pay to access the stimulus vixens and the average maximum price paid for contact was $38.3 \pm 8.3 \%$ of the price paid for food when hungry. During the time spent together, the stimulus foxes made use of their opportunity to leave the cage, on average $1.43 \pm 0.20$ times per visit. The behaviour recordings showed that during initial encounters the vixens would fight to establish dominance, and in four of the pairs the test subject emerged as the dominant individual. However, during subsequent interactions, no serious aggression was recorded and social behaviour was characterised by higher levels of sniffing and grooming $(23.7 \pm 4.3$ times $/ \mathrm{h}$ ), play signals $(10.5 \pm 4.1$ times/h) and agonistic displays $(5.5 \pm 2.5$ times $/ \mathrm{h})$. Not all of the time together was used for
\end{abstract}

* Corresponding author. Tel.: +47 649651 68; fax: +47 64965101.

E-mail address: anne.hovland@umb.no (A.L. Hovland). 
social interaction and during the observation period, the vixens allocated $33.1 \pm 6.9 \%$ of the time to synchronous resting. We conclude that young silver fox vixens were motivated for social contact, and that this contact was beneficial for welfare due to the low level of aggression and the occurrence of grooming and play.

(C) 2007 Elsevier B.V. All rights reserved.

Keywords: Social behaviour; Motivation; Operant method; Fox

\section{Introduction}

When farmed silver foxes (Vulpes vulpes) are kept commercially for fur production, breeding animals of both sexes are singly housed in wire mesh cages for most of the year. Breeding females (vixens) are normally housed singly except for 8 weeks each year when caring for their cubs and they may be kept for breeding purposes for up to 5 years. This is in contrast to the natural social structure of these animals. The wild counterpart of the silver fox is the red fox, a widespread member of the Canidae that occupies a broad range of habitats (Ables, 1975; Zimen, 1980; Baker and Harris, 2004). The social flexibility of red foxes is relatively well known (e.g. Macdonald, 1983; Cavallini, 1996). Family units may consist of: male-female pairs (e.g. Niewold, 1980), groups of one dominant male and several females (vixens) of varying social status, rarely including subordinate males (e.g. see Baker et al., 1998) and occasionally single mothers (e.g. Zabel and Spencer, 1989). However, in urban areas such groups may consist of up to 10 individuals (Baker et al., 2000) and multiple paternity may occur in 38-69\% of litters (Baker et al., 2004). In nature, single red fox vixens have great difficulties in raising their offspring (Zabel and Spencer, 1989) and sub-adult vixens may delay dispersal (e.g. von Schantz, 1981), resulting in a female-biased social group where several vixens share reproduction, or nonreproducing vixens act as helpers (Macdonald, 1979). In such groups, dominance relationships will affect the partition of roles (breeding or acting as a helper). However, for the establishment of such constellations, it is required that both vixens are motivated to do so, i.e. the motivation to form social bonds should be present. Social motivation in females may thus be the proximate mechanism responsible for the formation of such groups, a theory supported by the findings of Harris and White (1992) that more females than males were groomed (measured as the extent of chewing on ear tags) by other family members.

Farmed silver foxes will likewise form social groups when housed together in ground floor enclosures and their social and reproductive behaviour is similar to groups of wild red foxes, e.g. during autumn social distance and aggression increase between family members, paralleling the mechanisms responsible for dispersion in wild foxes (Ahola and Mononen, 2002). It is thus reasonable to believe that the motivation to socialise is present in farmed silver fox vixens. However, the strength of their motivation and their motives for social contact has not been investigated. Could enhanced social contact be beneficial for farmed vixens? Social contact appears to provide welfare benefits in other social species. For example, isolated rats show higher levels of stress (e.g. Hurst et al., 1998), as do isolated primates (e.g. Boccia et al., 1991; Novak et al., in press); the proximity of conspecifics can reduce stress responses to acute stimuli (e.g. in guinea pigs; Sachser et al., 1998); and social behaviours like grooming can have directly calming effects (e.g. in zebras and horses; Andersen, 1992; Feh and de Mazieres, 2003). In silver foxes themselves, it has been suggested that social housing may prove beneficial, especially during the summer, prior to the period of natural sub-adult dispersal (Ahola et al., 2002). However, potential 
problems, such as aggression may occur during social housing, both in farmed fox species (Ahola et al., 2000, 2001, 2005; Ahola and Mononen, 2002) and many other captive social animals housed in groups (e.g. pigs; Marchant et al., 1995; calves, heifers and cows; Bøe and Færevik, 2003). It is also clear that vixens can have other, more subtle detrimental effects on each other, e.g. reproductive suppression (Bakken, 1993).

One way of judging how the costs and benefits of social interaction compare is to quantify the animals' own preferences (e.g. Patterson-Kane et al., 2002). Operant methods are frequently used for measuring motivational strength and resource value in farm animals (e.g. Dawkins, 1983; Jensen et al., 2005). In general, the subjects are trained to perform various tasks (e.g. pulling a loop, pressing a lever) to access resources and measures of motivation are based on elasticity calculus (e.g. Matthews and Ladewig, 1994) or maximum operant responding (e.g. Bokkers et al., 2004; Cooper and Mason, 2001; Kirkden and Pajor, 2006). Food is frequently used as a 'yardstick' resource (e.g. Cooper and Appleby, 2003; Mason et al., 2001; Warburton and Mason, 2003). At present, the strength of social preferences in silver foxes is weakly documented (Hovland, 2005), and the aim of this experiment was to start investigating it in more detail. Our first aim was to examine whether vixens find contact with a conspecific reinforcing, and if so, to measure the strength of their motivation for social contact. To measure motivational strength for unrestricted social contact, our research group developed an operant apparatus in which subjects could work in a closed economy for bouts of access to a companion whose duration was unlimited (Hovland, 2005; Hovland et al., 2006a,b). The main motivational measure used was the 'maximum price paid' (e.g. Cooper and Mason, 2001), a valid index of motivation in a set-up such as ours, where animals could decide their own bout lengths when interacting with the test stimulus (Hovland et al., 2006a,b). In addition to such data, information on the behaviour of the animals is needed to examine their motives for seeking intraspecific contact, as a means to establish its potential welfare consequences. For instance, animals might seek social contact in order to establish or maintain dominance relations through aggression (e.g. during the mixing of unfamiliar pigs; Rushen, 1987), for play or other mutually beneficial activities (e.g. play in calves; Jensen and Kyhn, 1999; allogrooming in mink; Pedersen et al., 2004), or fearful individuals may seek others for protection or safety (e.g. grouping as an antipredator strategy in grazing sheep; Hansen et al., 2001). In our own operant studies, we found that male silver foxes tended to threaten another male, suggesting that socially housing males would not improve their welfare (Hovland et al., 2006a,b). Our second objective was thus to ascertain what behaviours occur between vixens during social interaction and whether this is affected by social status.

\section{Materials and methods}

\subsection{Experimental animals, feeding and housing}

Six 7-8 month old silver fox vixens from a standard commercial line acted as test subjects. Six vixens of the same age and origin were chosen as potential companions (i.e. 'stimulus foxes').

The test and stimulus foxes were originally selected from $34 \mathrm{cubs}$, pre-screened to confirm that they were suitable for testing in the apparatus (for details, see Section 2.3). From weaning to the start of training, these cubs were pair-housed in wire mesh cages measuring $75 \mathrm{~cm} \times 100 \mathrm{~cm} \times 110 \mathrm{~cm}$ with access to a resting shelf and an activity object. The cages were located inside a standard, uninsulated fox house. The cubs were fed ad libitum once a day and had free access to water from an automatic watering system. During training, cubs were housed in two separate training cages. Two different training cages were used because they contained different types of gates; one with flap doors only and the other with both flap doors and sliding doors. There were two food trays and two drinking cups inside the training cages and the cubs were fed $a d$ 


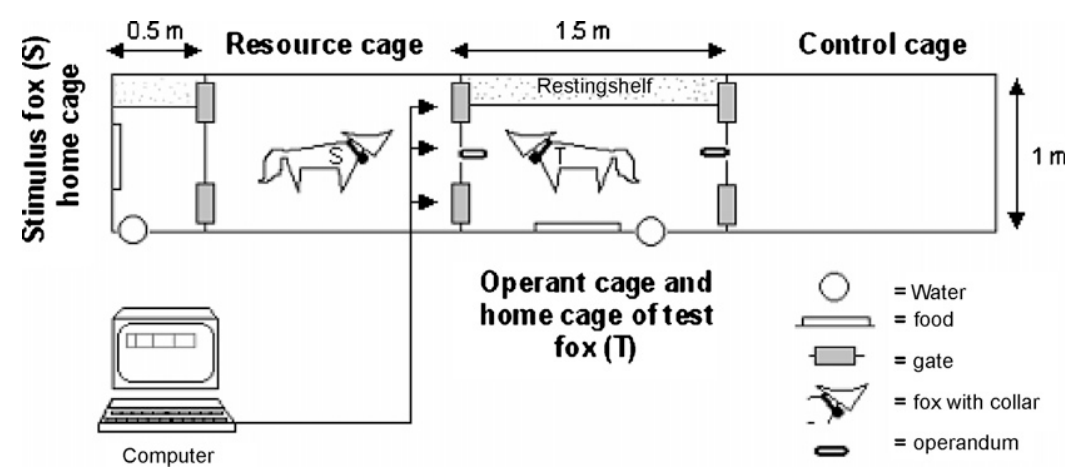

Fig. 1. The operant apparatus for foxes. During the social trial, the foxes had shared access to the resource cage. Further, the stimulus fox had exclusive access to the stimulus fox cage whereas the test fox had exclusive access to the operant compartment and the control cage. In the food trial, the test fox could access the resource cage and the control cage.

libitum once a day and water was replenished three times a day. Operant tests began at the age of 7-8 months. During these tests, the vixens were housed continuously inside the apparatus (Fig. 1). In between the trials, the subjects were singly housed in standard fox cages of the type described for cubs.

\subsection{Apparatus}

The operant apparatus consisted of four cage units made of standard, plastic-covered wire mesh (see Fig. 1). To ensure that social interaction only took place in the resource cage and to prevent the foxes from entering each other's home cages a door-lock system and collars were used (see details below). The central operant cage was attached to a resource cage and a control cage, and the stimulus fox home cage attached to the resource cage.

The operant cage was the test subject's home environment. Feeding trays, drinking cups and mesh resting platforms were mounted here and two operanda were located on opposite walls. The stimulus fox cage adjoining the resource cage was the home cage of the 'companion'. The space in this cage was restricted to motivate the stimulus fox (i.e. the resource) to stay inside the resource cage. This cage also contained feeding trays, drinking cups and platforms. The test subject had access to the resource cage and the control cage, but could not enter the stimulus fox cage. The 'companion' was allowed access to the stimulus fox cage and the resource cage only. During the experiment, increasing costs were imposed for access to the resource cage, but the control cage was always maintained at almost free access (FR1). This was to control for the effect of the extra space provided in the resource cage, and thus to ensure that motivation to access the resource cage could be attributed to the presence of the resource and not the cage itself. In this study, no data are presented on the test foxes' use of the control cage. Two aluminium one-way gates, one for entrance and one for exit connected each pair of cage units (for a more detailed description of the gates, see Hovland, 2005). All gates were equipped with a micro-switch for exact logging of time data. The test subjects and the stimulus foxes were provided with a collar for opening the exit gates. The collars were made of $3 \mathrm{~mm}$ thick polyethylene and were equipped with a transmitter in a PVC cover measuring $50 \mathrm{~mm} \times 30 \mathrm{~mm} \times 57 \mathrm{~mm}$. The total weight of collar and transmitter was $120 \mathrm{~g}$. Because some of the collars were chewed and destroyed during the social test, these were replaced by similar metal collars. A rubber-coated metal chain $(42 \mathrm{~cm})$ shaped as a loop, was chosen as the operandum. The force required for a validated pull could be varied, but was set at $0.5 \mathrm{~kg}$ force during the experiment. To register the number of completed pulls, a micro-switch was mounted on the operandum and connected to a computer interface (LabView, National Instruments). To allow the fox to enter the resource (or control) cage, the computer counted the required number of pulls and signalled to a gate controller mounted on top of the gate to open the door to the resource (or control) cage. During the experiment, the door was kept open for $10 \mathrm{~s}$ to allow the fox to enter before it was closed automatically. Each apparatus was mounted on stilts $1 \mathrm{~m}$ above ground level and a total of six units of the apparatus were used. They were placed $2 \mathrm{~m}$ apart in parallel rows inside the shed. Thus, the experimental animals could see and hear each other during the experiments. 


\subsection{Training procedure}

Training of the cubs was initiated just after weaning at 8 weeks of age. Thirty-four cubs were habituated to the presence of people and novel situations by daily hand-feeding of titbits and by providing access to various activity objects (elk bones, hemp ropes, empty soda bottles with pebbles, Swedish turnip). Four of the cubs were excluded from further training due to fear of people. The remaining $30 \mathrm{cubs}$, at the age of 4-6 months, were put into two training cages with gates and doors similar to those inside the operant apparatus, but without door locks. Because farmed silver foxes are easily startled by novelty, a domesticated silver fox male, already experienced with the operant apparatus, was housed together with each pair of cubs inside the training apparatus. The cubs and the male were housed for 1 week inside each of the training cages. The cubs that entered the gates successfully during the training session and behaved calmly (absence of aggressive attacks) when handled by humans were chosen for testing in the experimental apparatus. The test subjects and the stimulus foxes were trained separately.

During training of the test subjects the opening times of the motorized gates leading to the resource and control cages were gradually reduced from 30 to $10 \mathrm{~s}$. All of the vixens that pulled the operandum and visited the resource cage within 3 days were trained to pull the operandum for 5 weeks and were put on a steadily increasing response schedule up to DRH50 (for details see below) for proper establishment of the pulling response. To possibly elevate the subjects' motivation to enter the resource cage, a nest box was placed in the cage. At the end of the training session, all of the test subjects entered the resource cage at least once per day at DRH50. At the same time, the foxes had access to an empty control cage at FR1 and an additional selection criterion for test subjects was a minimum of one visit to this cage per $24 \mathrm{~h}$. A total of fourteen 6-month-old cubs were assessed as test subjects in the operant apparatus, and six of them reached the training criteria.

During training of the stimulus foxes the foxes had access to the gates leading to and from the stimulus fox cage. The criterion for choosing vixens as stimulus foxes was that they successfully entered the different gates more than five times during $24 \mathrm{~h}$. A total of eight vixens were tested as stimulus foxes, and six of them reached the training criterion within a $48 \mathrm{~h}$ period.

\subsection{Altering costs of access}

The reinforcement schedule used was 'differential reinforcement of high rates' (DRH; Chance, 1999), wherein a certain number of pulls must occur within a fixed amount of time. A punishing effect can thus arise if responding is too slow, or if the subject delivers pulls at random, because when the timer 'zeros out' the subject must start all over again to complete the schedule. The DRH schedule therefore ensures that the animal keeps on working at a constant rate, and it may generate extremely high rates of responding (Chance, 1999).

Based on previous tests (Hovland, 2005; Hovland et al., 2006a,b), a schedule allowing 4 s per pull was chosen. Prior to the start of trials, the foxes were put on a fixed ratio schedule of 1 (FR1) for a habituation period of 2-4 days. Subsequently, an ascending series of costs was imposed, the cost being increased every $24 \mathrm{~h}$ until the fox stopped visiting the resource. The cut-off used for calling it the maximum price paid was $24 \mathrm{~h}$. Then the response schedule was returned to FR1 for a minimum of 4 days, or until all of the remaining subjects had completed the trial. The costs were increased at 09:00 am each day using the following series: 1-4-8-16-32-48-64-80-96-112-128, and then costs were increased stepwise, with +32 until DRH544, then +64 until DHR992 and finally +96 until the maximum price was reached.

\subsection{Trial 1-motivation for unrestricted physical access to another vixen}

Prior to putting the animals within the apparatus a patch of fur on the tail of each test subject was removed for individual recognition. The stimulus animals were left unmarked. Subsequently, the collars were put on and the animals were placed inside the apparatus. Subjects were given 4 days to habituate to the apparatus and the stimulus fox on FR1 prior to the start of the trial, which ran between 10.12.2004 and 17.01.2005. The foxes were fed in the operant cage ad libitum once a day and water was replenished three times a day. 


\subsubsection{Behavioural recordings during Trial 1}

Subjects were videotaped continuously ( $24 \mathrm{~h}$ time-lapse) during the social trial using six video cameras. Due to the daylight conditions and the low picture quality caused by the wire mesh, behaviour was only observable between 09:30 and 15:00. We did not use artificial light because of practical limitations (the size of the barn).

Behaviour during social interaction was recorded continuously at four different cost levels (low-medium1medium 2-high). Because several of the behaviours appeared at low frequencies, behaviours were pooled across all cost levels. Observation time was not standardised because the test subjects decided their own visit duration. For instance, at high cost levels subjects tended to visit during the dark hours when behaviour observation was not possible. Thus, total observation time for social interaction varied between pairs, from a minimum of $70 \mathrm{~min}$ to a maximum of $345 \mathrm{~min}$, with a mean of $198 \pm$ S.D. $122 \mathrm{~min}$ for each pair.

To investigate the test subjects' motives for seeking physical contact, behaviours related to competition, play, synchronous resting and exploration were recorded (Table 1). Apart from synchronous resting, behaviour was recorded as an event each time it occurred regardless of its duration, and as a new event when it was interrupted by any other behavioural acts. Synchronous resting was recorded as a state and the relative portion of time each pair spent resting together during the observation period was calculated. The frequency of the behaviours was calculated based on active time (i.e. total observation time minus time spent in synchronous resting). In addition, agonistic postures (Table 2) during the first $2-4$ encounters between the test subject and the companion (on the first and second experimental days) were observed, to determine the dominance relation within each pair (e.g. Meyer and Weber, 1996). Using this method, it was possible to establish the dominance relationship in four of the six pairs. In pair 3 none of the first encounters were of sufficient quality for behavioural recording, while in pair 6 only one encounter was available.

Table 1

Ethogram of behaviours recorded during social interaction

\begin{tabular}{|c|c|}
\hline Behaviour & Description \\
\hline \multicolumn{2}{|l|}{ Play related signals } \\
\hline Pounce & One fox suddenly jumps onto the back of the other in a rapid movement \\
\hline Jump towards ('lunge') & $\begin{array}{l}\text { One fox jumps suddenly towards the other with body stretched upwards and forepaws } \\
\text { clearly elevated }\end{array}$ \\
\hline Sideways jump & Sudden, low jump sideways \\
\hline Side wrestling & Both individuals lie on their side and play wrestle \\
\hline Play wrestling & Wrestling and tumbling during play interaction \\
\hline \multicolumn{2}{|l|}{ Agonistic signals } \\
\hline Mount & One fox mounts the other \\
\hline Agonistic gape & Open mouth signal directed towards other fox (not 'open-mouthed play face') \\
\hline Mutual upright stabbing & $\begin{array}{l}\text { Mutual forepaw stabbing and pushing. The foxes stand on their hind legs, ears } \\
\text { turned backwards, seizing each other with the front paws, pushing and displaying } \\
\text { threat-related gapes (see Macdonald (1987), p. 103, bottom figure). }\end{array}$ \\
\hline Physical fight & Attack followed by wrestling and bites directed towards neck region of opponent \\
\hline \multicolumn{2}{|l|}{ Neutral signals } \\
\hline \multicolumn{2}{|l|}{ Nose-to-nose contact } \\
\hline Sniff/groom & The fox sniffs and/or grooms the other \\
\hline \multicolumn{2}{|l|}{ Synchronous resting } \\
\hline Rest without contact & Both foxes are curled up in a typical 'rest position' at a distance of $>50 \mathrm{~cm}$ \\
\hline Rest close & Both foxes are curled up in a typical 'rest position' at a distance of $\leq 50 \mathrm{~cm}$ \\
\hline Rest with contact & Both foxes are curled up in a typical 'rest position', with physical contact \\
\hline \multicolumn{2}{|l|}{ Other } \\
\hline Explore locked gates & The test fox puts its head and body into the stimulus fox's gate and tries to enter it \\
\hline
\end{tabular}


Table 2

Ethogram of postures during agonistic interaction between silver fox vixens that were used for determination of the dominance relation between the test subject and the stimulus fox

\begin{tabular}{ll}
\hline Behaviour & Description \\
\hline Upright (mutual) & $\begin{array}{l}\text { Both foxes stand on their hind legs, ears turned backward. A high-intensity agonistic } \\
\text { posture that is followed by physical attack if the opponent does not withdraw } \\
\text { (see also Table 1) }\end{array}$ \\
The fox stands stiff on four legs, arching its back with the head pointing downwards and \\
Piloerection and \\
back arching \\
the opponent and displaying the flank (side), or moderate the signal by looking away and \\
pointing its hind part towards the opponent (see Fox (1971), p. 41, Fig. 4b for a parallel \\
display in grey fox Urocyon cinereoargenteus). The more dominant fox normally uses \\
this display \\
The fox has a low body and head posture where the back is arched and curved and the legs \\
are crouched. The ears are turned backwards (flat), the mouth is open, and the tail is low \\
and may swipe back and forth (see Macdonald (1987), p. 42, bottom right figure) \\
The fox has a low body and head posture and may lie down, but not crouch or curve its \\
posture
\end{tabular}

\subsubsection{Other data collected in Trial 1}

The number of visits to the resource cage per cost, total time spent inside the resource cage per cost and mean visit duration to the resource cage per cost were calculated for the test subject and the stimulus fox. Since the stimulus fox was free to leave the resource cage when the test fox was present, we also calculated total time spent together in the resource cage per cost. To describe the pattern of social interaction when contact was almost free (FR1) the above-mentioned time and visit variables were also calculated for the test fox and the stimulus fox at FR1. These measures were calculated based on five $24 \mathrm{~h}$ periods on FR1: the first day on FR1 and four consecutive days at FR1 after the maximum price had been paid. In one pair of foxes, only the four last FR1 days were used because the test fox was taken out of the apparatus on the first day for treatment of a superficial wound, and this handling may have affected its behaviour. For one of the stimulus foxes, visit number and mean visit duration were calculated based on 2 days due to a logging error that occurred at the end of the experiment.

The foxes tended to gnaw each other's collars with the result that we had to replace some of the collars during the social experiment. Damage caused by gnawing on ear tags has previously been used as an indicator of social grooming in free-living red foxes (Harris and White, 1992), since such damage does not occur during aggression, which is normally directed at other body parts. As a possible predictor of the direction of social grooming, we therefore recorded each instance of collar replacements, including the identity of the fox that had its collar replaced.

Because the stimulus fox was free to leave the operant cage during interactions, such terminations could possibly have reflected aspects of social tension between the animals. For example, if the motive for visiting was to maintain dominance, such visits could potentially be experienced as threatening by the stimulus fox, thus increasing its motivation to leave the cage. We therefore calculated the number of terminations by the stimulus fox by counting the number of times it left the cage when both foxes were present. To standardise this measure, we calculated relative visit terminations per cost and pair by dividing the number of interruptions made by the stimulus fox by the number of visits made by the test subject. For example, if the stimulus fox interrupted each visit once this value would equal 1 , and if each visit was interrupted more than once this value would be greater than 1. 'Relative visit termination' was also calculated when visits were almost free, based on 5 days on FR1 following the same procedure as mentioned for the other FR1 variables (see above). 


\subsection{Trial 2-motivation for access to food}

To examine the relative motivational strength for social contact, the vixens' maximum price paid for access to food, a commonly used yardstick resource was measured. The subjects were given 2 days for habituation on FR1 inside the apparatus prior to the start of the experiment. The cost level was increased at 09:00 am each day, on the same schedules as used in Trial 1. No stimulus foxes were present during this test.

The food was provided in a bowl tethered to the wire mesh floor inside the resource cage. The ration size was determined after feeding the foxes $500 \mathrm{~g}$ standard wet paste for fur animals (Pelsdyrfôr Hamar AB) for 3 days and recording their intake; a ration of between 400 and $450 \mathrm{~g}$ was then delivered at approximately 09:15 each day. During the experiment, the intake of individual subjects was also monitored on a daily basis. If some of the food remained uneaten on 2 consecutive days, the ration was slightly reduced to avoid a possible loss of appetite (Hovland et al., 2006b). The food was a standard wet paste for fur animals consisting of $50 \%$ protein, $33 \%$ fat and $17 \%$ carbohydrate with a metabolizable energy content of $115 \mathrm{kcal} /$ $100 \mathrm{~g}$. Water was available from drinking cups in the operant cage and was replenished three times a day. The trial ran from 25.01.2005 to 14.03.2005.

\subsection{Data collected in both trials}

In both trials, the maximum price paid was recorded as the price paid the day before the foxes stopped visiting the resource. The relative maximum price for contact was calculated as the maximum price for social contact divided by the maximum price for food.

\subsection{Statistical analyses}

The time and visit data were analysed using paired-samples $t$-tests (SAS, 1990). To assess how increasing access costs affected the test foxes' use of the resource cage, the regression lines for each fox were calculated for the number of visits, total time in the resource compartment, mean visit duration and total time spent together with the stimulus fox against the costs as increased every $24 \mathrm{~h}$. Gradients were then compared with no decline using a one-sample $t$-test against an expected slope of zero. The same procedure was also used to assess whether the stimulus foxes use of the resource cage was affected by the reduced visits from the test fox. To remove skewness from the data, the variables 'number of visits' and total time spent together' were log-transformed. Correlations between variables of interest were investigated using Pearson correlation tests. A Wilcoxon Signed-Ranks test was used to test differences in number of collar changes between the test and stimulus fox. All mean values are given with standard errors (SE). SAS ${ }^{\mathbb{R}}$ Enterprise GuideV2 was used for the statistical analyses.

\subsection{Ethical note}

In Trial 1 of this study, all foxes had the opportunity to withdraw from further contact and potential aggression from the neighbour by retreating to their respective home cages. However, at the start of Trial 1 the foxes would fight; during this time the animals were observed continuously with the potential use of intervention for the five first hours. Except for one test fox that was treated for a superficial wound, no animals were injured during this period or during rest of the study. In both trials, the foxes were checked visually by the animal caretaker three times a day. In this study, the 'cut-off' for calling an FR the maximum price paid was that the foxes stopped visiting the resource for $24 \mathrm{~h}$. In Trial 2, this implied that the foxes were denied food for 1 day. Subsequent to recording their maximum price paid, the cost was set to FR1 and, to compensate, they were offered extra food. The foxes were weighed before and after the study and the body weight of all but one of the vixens remained stable or increased $(0-0.5 \mathrm{~kg})$. According to the Norwegian regulations for fur animals (Chapter I, § 9), foxes should be fed at least once per $24 \mathrm{~h}$. This study was part of a project on social motivation in farm silver foxes that was approved by the Norwegian Animal Research Authority. 


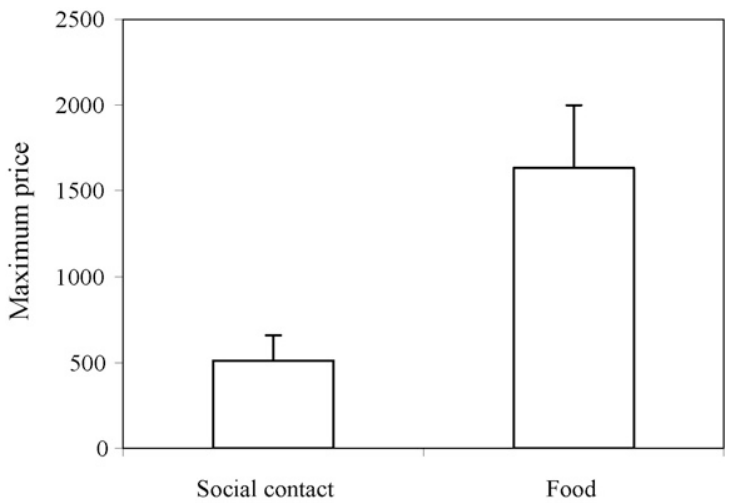

Fig. 2. The silver fox vixens' maximum price paid for visiting a same-age vixen and food $(P=0.014)$.

\section{Results}

\subsection{Motivation for unrestricted access to a companion}

The subjects were willing to pay for unrestricted access to another vixen (Fig. 2). The maximum price paid for social contact was significantly less than the maximum price paid for food $\left(T_{5}=3.68, P=0.014\right)$. The maximum price paid for contact was approximately $38.3 \pm 8.3 \%$ of the price paid to access food, although this varied individually from 12 to $60 \%$.

\subsection{Visits to the resource cage and time spent together when visits were almost free (FR1)}

Total interaction time and total time spent in the resource cage at FR1 for the test subjects and the stimulus foxes are shown in Fig. 3. On average, pairs spent almost half of the day together. The stimulus foxes tended to spend more time in the resource cage compared to the test foxes $\left(T_{5}=2.41, P=0.061\right)$. At FR1 the test subjects visited the resource cage on average $30.3 \pm 4.3$

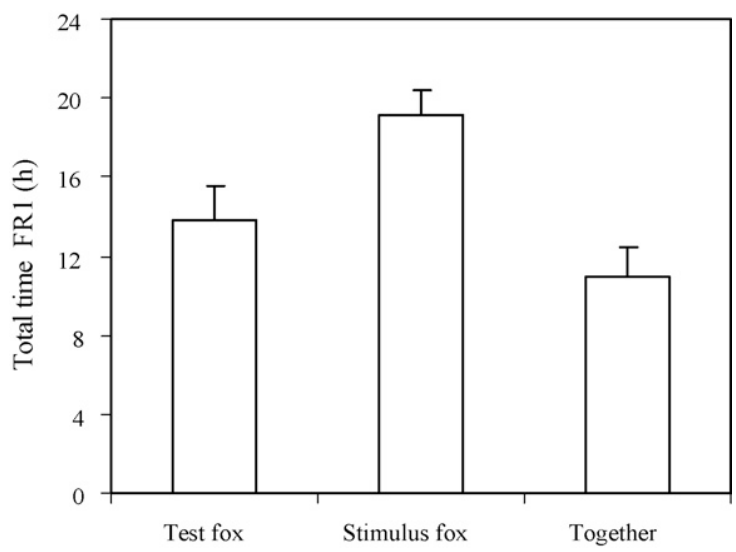

Fig. 3. Mean total time spent inside the resource cage for the test and stimulus fox when the test fox' access costs were low (a fixed ratio schedule of 1, FR1) and mean total time spent together per $24 \mathrm{~h}$. The values are calculated from five $24 \mathrm{~h}$ periods on FR1; the first day on FR1 and four consecutive days at FR1 after the maximum price was paid. 

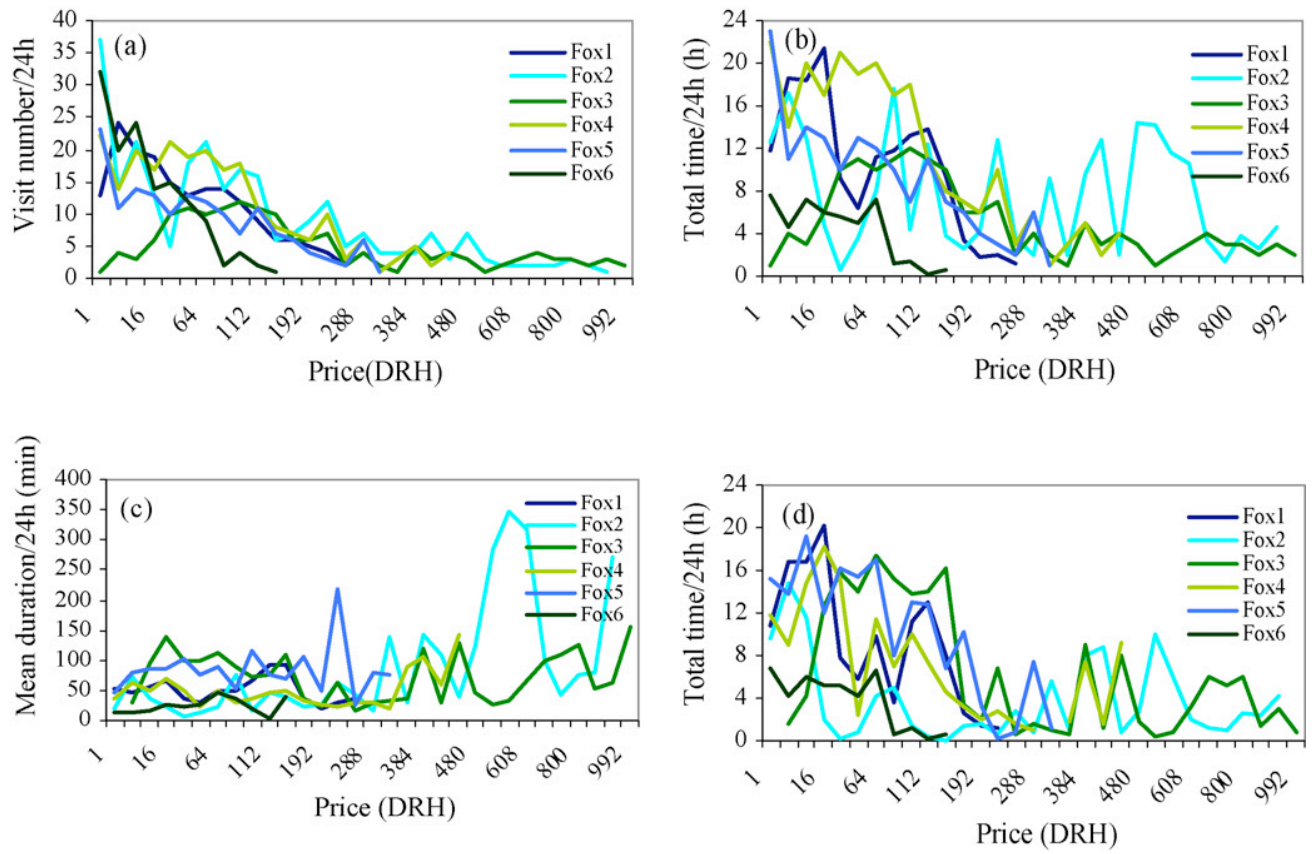

Fig. 4. Changes in the test subjects' (a) visit number to the resource cage with increasing costs, (b) total time spent in the resource cage with increasing costs and (c) mean duration of visits to the resource cage with increasing costs. (d) Change in the total time spent interacting with increasing costs.

times, compared with $40.7 \pm 9.6$ for the stimulus foxes $\left(T_{5}=0.94, P=0.391\right)$. The test subjects' mean visit duration to the resource cage was $38 \operatorname{min~} 19 \mathrm{~s} \pm 11 \min 41 \mathrm{~s}$, while it was $41 \mathrm{~min}$ $58 \mathrm{~s} \pm 8 \mathrm{~min} 52 \mathrm{~s}$ for the stimulus foxes $\left(T_{5}=0.23, P=0.824\right)$.

\subsection{Visits to the resource cage and time spent together with increasing access costs}

All test subjects visited the resource cage less frequently with increasing costs $\left(T_{5}=6.88\right.$, $P=0.001$; Fig. 4a) and they spent less total time inside the resource cage when access cost was raised $\left(T_{5}=3.26, P=0.023\right.$; Fig. $\left.4 \mathrm{~b}\right)$. There was no significant increase in mean visit duration to the resource cage with increasing costs $\left(T_{5}=1.46, P=0.203\right.$; Fig. $\left.4 \mathrm{c}\right)$. As a consequence of the reduced time spent inside the resource cage, total time spent together with the stimulus fox also decreased with increasing costs $\left(T_{5}=3.15, P=0.025\right.$; Fig. 4 d $)$.

Neither the stimulus foxes' visit frequencies, nor the total time they spent inside the resource cage, were affected by the reduction in visits from the test subject that occurred as costs increased (visits: $T_{5}=1.0, P=0.363$; total time: $T_{5}=1.0, P=0.363$ ). The stimulus foxes' mean visit durations were also not significantly affected by the reduced visit frequency of the test subject $\left(T_{5}=1.0, P=0.363\right)$.

\subsection{Termination of visits by the stimulus fox}

The mean number of visit terminations by the stimulus fox when visits were almost free (FR1) was $39.3 \pm 2.6$ and the relative visit termination rate was $1.43 \pm 0.20$ times per visit (Table 3 ). 
Table 3

The dominance relation within pairs of foxes based on number and type of agonistic displays during the first encounters ( $N=$ number of encounters). Dominant animals signified in bold text. Also, direction of grooming is estimated by showing the frequency of individual collar replacements that were performed during the study. The stimulus fox's tendency to terminate visits by leaving the resource cage (at FR1) is shown as a relative value (value $>1=$ each visit interrupted more than once)

\begin{tabular}{|c|c|c|c|c|c|c|c|}
\hline Pair & Animals & $N$ & Upright (mutual) & Piloerection & Submissive & Collar replacement & Terminate \\
\hline \multirow[t]{2}{*}{1} & Test fox & 4 & 8 & 19 & 0 & 0 & \\
\hline & Stimulus fox & & & 0 & 30 & 1 & 1.96 \\
\hline \multirow[t]{2}{*}{2} & Test fox & 4 & 5 & 11 & 0 & 0 & \\
\hline & Stimulus fox & & & 0 & 13 & 1 & 0.89 \\
\hline \multirow[t]{2}{*}{3} & Test fox ${ }^{a}$ & & - & - & - & 0 & \\
\hline & Stimulus fox & & & & & 1 & 1.10 \\
\hline \multirow[t]{2}{*}{4} & Test fox & 2 & 0 & 0 & 0 & 0 & \\
\hline & Stimulus fox & & & 0 & 12 & 5 & 1.03 \\
\hline \multirow[t]{2}{*}{5} & Test fox & 3 & 3 & 11 & 0 & 0 & \\
\hline & Stimulus fox & & & 0 & 8 & 2 & 2.00 \\
\hline \multirow[t]{2}{*}{6} & Test fox & 1 & 9 & 0 & 0 & 0 & \\
\hline & Stimulus fox ${ }^{b}$ & & & 1 & 0 & 2 & 1.65 \\
\hline
\end{tabular}

${ }^{\mathrm{a}}$ Test fox was observed mounting the stimulus fox three times during two later observations (DRH320 (1) and DRH448 (2)).

${ }^{\mathrm{b}}$ Stimulus fox was observed mounting the test fox once during this encounter.

When the termination rate was calculated based on the five highest cost levels, it was $2.49 \pm 0.24$ times per visit $\left(T_{5}=3.04, P=0.029\right)$.

\subsection{Behaviour during social interaction}

The occurrence of different behaviours was not significantly correlated with observation time ( $n=6, P>0.143$ ), except for sniffing and grooming $(r=0.83, n=6, P=0.043)$. Fig. 5 shows the behavioural categories that were recorded during social interaction within daylight hours. All of the test subjects performed at least one of the distinct behaviours belonging to each behavioural

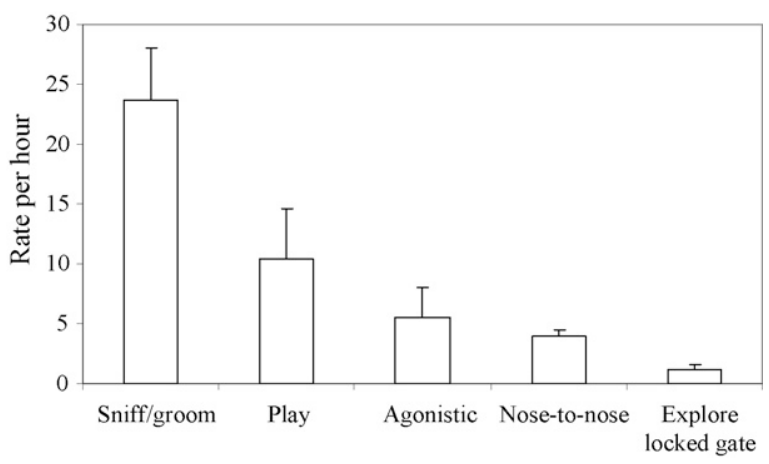

Fig. 5. Total occurrence of different behaviours during the foxes' social interaction. The values are calculated as rate per hour active time (active time = observation time minus time spent in synchronous resting). The columns represent mean \pm S.E. occurrence of behaviours recorded at four separate cost levels. 
category except 'Explore locked gate', which was recorded in five of the test subjects. In total, the foxes spent $33.1 \pm 6.9 \%$ of the entire observation time in synchronous resting, and this behaviour was recorded in five of the pairs. Resting without contact and resting close were the most common resting positions and were performed $12.8 \pm 7.1$ and $15.0 \pm 6.8 \%$ of the observation time, respectively. Resting with contact was observed in only two of the pairs. No incidents of physical fights were recorded after the initial aggressive encounters at FR1.

\subsection{Dominance relations and other asymmetries between the test and stimulus foxes}

Based on the frequency of submissive and dominant postures during the first encounters, the test fox was determined the dominant animal in four of the pairs (Table 3). To test whether initiation of some of the social behaviours differed according to social status, data from the pairs where dominance relations were established were analysed $(n=4)$. None of the behaviours was significantly affected by status $(P>0.300)$. However, cases of mounting were mainly observed in the dominant vixens. All of the test subjects chewed significantly more on the stimulus fox's collar (Wilcoxon, $Z=3.1, P=0.002$; Table 3). The collars of all the stimulus foxes were replaced at least once during the study, whereas none of the test subjects collars were changed (Table 3 ).

\section{Discussion}

Our results show that farmed silver fox vixens will perform operant work for unrestricted physical access to a same-age vixen. They thus find access to another female reinforcing. Furthermore, when access to the stimulus fox was almost free, they visited the resource cage frequently and spent almost half the day together with the companion. The relative motivation for contact, measured as the maximum price paid, constituted approximately one-third of their motivation to access food, although this varied between the subjects. The experimental set-up imitated a standard housing system for farmed silver foxes in which foxes can see and hear each other, and thus their motivation to access other foxes was likely affected by resource cues (Warburton and Mason, 2003). Thus, our results do not reveal whether silver fox vixens would miss social contact if fully isolated, but they do describe short-term patterns of satiation and deprivation that occur during the course of a day when social cues are available. As suggested by Warburton and Mason (2003), testing animals in the presence of resource cues should be valid when addressing the applied question 'how motivated are foxes to interact with neighbouring foxes when they can see and hear each other'. Thus our results show that in standard farm conditions, where social cues surround them, vixens are motivated to have full social contact.

What motivated such interactions, and did such motivations vary between the test and stimulus fox? Typically, the vixens would fight during the initial encounters, but serious aggression was not recorded thereafter. During subsequent social interactions, behaviour was characterised by higher levels of social sniffing and grooming, play signals and agonistic displays. The most frequent agonistic display used by the vixens was the gaping signal, which serves to regulate social distance in red foxes (Fox, 1971). Social grooming (or allogrooming) may, besides having a potential hygienic function, serve to establish or maintain social bonds in mammals (e.g. reviewed by Spruijt et al., 1992) and have calming and/or rewarding properties (e.g. it is a positive reinforcer for monkeys; Taira and Rolls, 1996). Similarly, play may act to establish social bonds in animals (e.g. Bekoff, 1974) and may be experienced as rewarding (e.g. Van Ree et al., 2000). However, not all of the time spent together was used for social interaction. About $33 \%$ of the time, foxes stayed together in the shared cage were spent in synchronous 
resting. This may have reflected a mutual motivation to stay inside the shared compartment for subsequent social interaction. Alternatively, the presence of a conspecific may also have had a calming effect (cf. 'social support': whereby, e.g. social contact reduces cortisol responses in guinea pigs; Hennessy et al., 2006) that possibly motivated both foxes to prolong their stay despite not being engaged in specific social interactions. Also, the test subjects sometimes investigated the locked gates leading to the stimulus fox's home cage, possibly implying a motivation to explore the stimulus fox's area.

Interestingly, in the four dyads for which we could judge a ranking our test subjects were socially dominant. This finding could indicate that subordinate vixens may be harder to train successfully in the apparatus, maybe because they have higher fear levels and are less explorative, with the consequence that they spend more time learning how to operate the apparatus. Consistent with this, Boissy and Le Neindre (1990) have observed reduced operant performance in fearful heifers. Alternatively, because the test subjects were housed for longer in the apparatus during training, and also were trained first, they may have perceived themselves to be 'residents' and would therefore have fought harder to maintain their residency (cf. increased aggression towards intruders in resident female Ozark zigzag salamanders, Plethodon angusticlavius, Mathis et al., 2000).

Grooming, measured as the degree of chewing on and subsequent replacement of the collar, was directed mainly towards the stimulus foxes. There was no difference in the observed level of sniffing and grooming between the test fox and the stimulus fox during the daylight hours, but collars were usually replaced in the morning, indicating that extensive grooming bouts took place in the evenings and during the night. In a study of dispersal in red foxes, Harris and White (1992) used the extent of chewing on plastic ear tags as an indirect measure of grooming and affiliative behaviour in a group of red foxes in the urban area of Bristol, UK. If the degree of chewing on the collar in our study was a true measure of the extent of grooming, our results suggest that some forms of grooming are part of the dominant behavioural repertoire in farmed silver fox vixens. This might be expected if gnawing on the collar required the recipient of 'grooming' to assume an immobile posture for a long period, which is more likely if the recipient is subdominant. However, in another study on social motivation in silver fox males (Hovland, 2005), conducted at the same period as the current social test and using the same type of collars, none of the collars $(n=3)$ needed to be replaced because they were not chewed to the same extent (personal observation). Harris and White (1992) found that females were groomed to a greater degree than were males, a finding that is in accordance with our observations and which indicates that vixens spend more time performing affiliative behaviour and may form stronger social bonds compared to males.

In operant set-ups where subjects are free to decide their own bout length increasing costs may lead to behaviour rescheduling where the animal prolongs visit duration to compensate for the increased access fees (Cooper and Mason, 2000). In this study, there was no such significant increase in visit duration with increasing costs in contrast to a previous study by Hovland et al. (2006a,b) where male foxes worked for social proximity and prolonged their visits when costs were raised. One reason for not prolonging social visits may be that our subjects had access to unrestricted social contact and thus were more easily satiated, as compared to studies where animals are just allowed restricted contact. Alternatively, to compensate, the foxes could have intensified their social interaction instead of prolonging visits (cf. reducing 'dead-time', Cooper and Mason, 2001); however, our behavioural data were not sufficient to test this prediction.

An important aspect of the foxes' social interactions was the stimulus fox's opportunity to terminate the visits, and our data showed that they used their opportunity to leave the resource 
cage one to two times per visit when visits from the test fox were frequent (at FR1) and two to three times per visit when visits from the test fox were less frequent (at high costs). The motivation to withdraw from social contact could have been to avoid aggression from the test fox; alternatively, withdrawal might have been used as a submissive signal. Because aggression was rare and the agonistic behaviour observed mainly consisted of gaping signals the withdrawal opportunity may have acted as a potential 'buffer' against further aggression. One alternative explanation for the stimulus foxes' active use of the home cage could be its mere availability. This is supported by the fact that the stimulus foxes' visits to the home cage were often of short duration and were occasionally seen during play sessions (personal observation), aspects that do not support the idea that they used the cage for protection from aggression.

In regard to the social motivation of the stimulus fox, the results showed that time spent in the resource cage was unaffected by the reduction in visits from the test fox. This could suggest that the stimulus foxes were not motivated to be alone, and thus continued to stay in the resource cage to get close to the test fox. Alternatively, continuing to stay in the resource cage could imply that motivation to be social or to be alone was not the only precondition for the stimulus fox's decision to enter the resource cage. Possibly, the stimulus foxes were also motivated to access the resource cage to perform locomotor behaviours because of the restricted space in their home cages.

We conclude that our test subjects were motivated for social contact and that the occurrence of play and low levels of overt aggression show that silver fox vixens may benefit from social contact with another same-age vixen, at least until some weeks prior to the start of the breeding season. However, further questions need to be addressed before making specific recommendations for fur farms. The first is how such motivations change over time: our trial ended 2-4 weeks prior to the beginning of their reproductive period, and it would be interesting and important to examine how the nature and strength of social motivation change with reproductive status. The second is the issue of individual variation in social motivation: are some foxes inherently more sociable than others, or is social motivation more a product of the characteristics of the potential partner? An important issue to emphasise is that our subjects had the opportunity to leave the shared compartment, and could withdraw from further contact whenever they chose. To investigate whether such opportunities for control are important for well-functioning relationships, the welfare consequences of pair-housing silver fox vixens given various opportunities to withdraw from contact should be examined in future studies.

\section{Acknowledgements}

This study was supported by the Norwegian Research Council and the Norwegian Fur Breeders' Association. We are grateful to research assistant Helene Kingsley Smith for her assistance in completing the behaviour recordings and to Dr. Inger Lise Andersen for her advice in relation to behaviour recording. Thanks to the staff at the research farm for taking good care of the animals. We also thank Andreas Flø and Tore Ensby at Department of Mathematical Sciences and Technology for help with computing the time data and for assistance with the collars.

\section{References}

Ables, E.D., 1975. Ecology of the red fox in North America. In: Fox, M.W. (Ed.), The Wild Canids. Their Systematics, Behavioural Ecology and Evolution. Van Nostrand Reinhold Co., New York, pp. 216-236. 
Ahola, L., Harri, M., Kasanen, S., Mononen, J., Pyykonen, T., 2000. Effect of family housing of farmed silver foxes (Vulpes vulpes) in outdoor enclosures on some behavioural and physiological parameters. Can. J. Anim. Sci. 80, 427434.

Ahola, L., Harri, M., Mononen, J., Pyykonen, T., Kasanen, S., 2001. Welfare of farmed silver foxes (Vulpes vulpes) housed in sibling groups in large outdoor enclosures. Can. J. Anim. Sci. 81, 435-440.

Ahola, L., Mononen, J., 2002. Family break-up in farmed silver foxes (Vulpes vulpes) housed in enlarged cage systems as families. Acta Ethol. 4, 125-127.

Ahola, L., Mononen, J., Pyykonen, T., Mohaibes, M., Rekila, T., 2002. Effects of group size and space allocation on physiological, behavioural and production-related welfare parameters in farmed silver fox cubs. Agric. Food Sci. Finland 11, 185-197.

Ahola, L., Mononen, J., Pyykonen, T., Mohaibes, M., Hänninen, S., 2005. Group size and space allocation in farmed juvenile blue foxes (Alopex lagopus). Anim. Welf. 14, 1-9.

Andersen, K.F., 1992. Size, design and interspecific interactions as restrictors of natural behavior in multispecies exhibits. 1. Activity and intraspecific interactions of Plains zebra (Equus-burchelli). Appl. Anim. Behav. Sci. 34, $157-174$.

Baker, P.J., Robertson, C.P., Funk, S.M., Harris, S., 1998. Potential benefits of group living in the red fox, Vulpes vulpes. Anim. Behav. 56, 1411-1424.

Baker, P.J., Funk, S.M., Harris, S., White, P.C.L., 2000. Flexible spatial organisation of urban foxes, Vulpes vulpes, before and during outbreak of sarcoptic mange. Anim. Behav. 59, 127-146.

Baker, P.J., Funk, S.M., Bruford, M.W., Harris, S., 2004. Polygynandry in a red fox population: implications for the evolution of group living in canids? Behav. Ecol. 15, 766-778.

Baker, P.J., Harris, S., 2004. Red foxes. The behavioural ecology of red foxes in urban Bristol. In: Macdonald, D.W., SilleroZubiri, C. (Eds.), Biology and Conservation of Wild Canids. Oxford University Press, pp. 207-216.

Bakken, M., 1993. Reproduction in farmed silver fox vixens, Vulpes vulpes, in relation to own competition capacity and that of neighbouring vixens. J. Anim. Breed. Genet. 110, 305-311.

Bekoff, M., 1974. Social play and play-soliciting by infant canids. Am. Zool. 14, 323-340.

Boccia, M.L., Reite, M.L., Kaemingk, K., Held, P., Laudenslager, M.L., 1991. Social-context and reaction to separation in peer-reared pigtail macaques-some preliminary observations. Primates 32, 255-263.

Boissy, A., Le Neindre, P., 1990. Social influences on the reactivity of heifers: implications for learning abilities in operant conditioning. Appl. Anim. Behav. Sci. 25, 149-165.

Bokkers, E.A.M., Koene, P., Rodenburg, T.B., Zimmermann, P.H., Spruijt, B.M., 2004. Working for food under conditions of varying motivation in broilers. Anim. Behav. 68, 105-113.

Bøe, K.E., Færevik, G., 2003. Grouping and social preferences in calves, heifers and cows. Appl. Anim. Behav. Sci. 80, 175-190.

Cavallini, P., 1996. Variation in the social system of the red fox. Ethol. Ecol. Evol. 8, 323-342.

Chance, P., 1999. Learning and Behaviour. Brooks/Cole Publishing Company, USA.

Cooper, J.J., Appleby, M.C., 2003. The value of environmental resources to domesticated hens: a comparison of the workrate for food and for nests as a function of time. Anim. Welf. 12, 39-52.

Cooper, J.J., Mason, G.J., 2000. Increasing costs of access to resources cause rescheduling of behaviour in American mink (Mustela vison): implications for the assessment of behavioural priorities. Appl. Anim. Behav. Sci. 66, $135-151$.

Cooper, J.J., Mason, G.J., 2001. The use of operant technology to measure behavioural priorities in captive animals. Behav. Res. Methods Instrum. Comput. 33, 427-434.

Dawkins, M.S., 1983. Battery hens name their price: consumer demand theory and the measurement of ethological 'needs'. Anim. Behav. 31, 1195-1205.

Feh, C., de Mazieres, J., 2003. Grooming at a preferred site reduces heart rate in horses. Anim. Behav. 46, 1191-1194.

Fox, M.W., 1971. Behaviour of Wolves, Dogs and Related Canids. Jonathan Cape Ltd., London.

Hansen, I., Christiansen, F., Hansen, H.S., Braastad, B.O., Bakken, M., 2001. Variation in behavioural responses of ewes towards predator-related stimuli. Appl. Anim. Behav. Sci. 70, 227-237.

Harris, S., White, P.C.L., 1992. Is reduced affiliative rather than increased agonistic behaviour associated with dispersal in red foxes? Anim. Behav. 44, 1085-1089.

Hennessy, M.B., Hornschuh, G., Kaiser, S., Sachser, N., 2006. Cortisol responses and social buffering: a study throughout the life span. Horm. Behav. 49, 383-390.

Hovland, A.L., 2005. Development and evaluation of an operant method to measure social motivation in farmed silver foxes (Vulpes vulpes). Dr. Scientiarum Thesis. 14, Norwegian University of Life Sciences, ISBN 82-575-0656-7, ISSN 0802-3220.

Hovland, A.L., Mason, G., Bøe, K.E., Steinheim, G., Bakken, M., 2006a. Evaluation of the 'maximum price paid' as an index of motivational strength for farmed silver foxes (Vulpes vulpes). Appl. Anim. Behav. Sci. 100, $258-279$. 
Hovland, A.L., Mason, G., Ahlstrøm, Ø., Bakken, M., 2006b. Responses of farmed silver foxes (Vulpes vulpes) to excessive food availability: implications for using food as a yardstick resource in motivation tests. Appl. Anim. Behav. Sci., doi:10.1016/j.applanim.2006.10.012.

Hurst, J.L., Barnard, C.J., Nevison, C.M., West, C.D., 1998. Housing and welfare in laboratory rats: the welfare implications of social isolation and social contact among females. Anim. Welf. 7, 121-136.

Jensen, M.B., Kyhn, R., 1999. Play behaviour in group-housed dairy calves, the effect of space allowance. Appl. Anim. Behav. Sci. 67, 35-46.

Jensen, M.B., Pedersen, L.J., Munksgaard, L., 2005. The effect of reward duration on demand functions for rest in dairy heifers and lying requirements as measured by demand functions. Appl. Anim. Behav. Sci. 90, $207-217$.

Kirkden, R.D., Pajor, E.A., 2006. Motivation for group housing in gestating sows. Anim. Welf. 15, 119-130.

Macdonald, D.W., 1979. 'Helpers' in fox society. Nature 282, 69-71.

Macdonald, D.W., 1983. The ecology of carnivore social behaviour. Nature 301, 379-384.

Macdonald, D.W., 1987. Running With the Fox. Unwin Hyman, London.

Marchant, J.N., Mendl, M.T., Rudd, A.R., Broom, D.M., 1995. The effect of agonistic interactions on the heart rate of group-housed sows. Appl. Anim. Behav. Sci. 46, 49-56.

Mason, G.J., Cooper, J., Clarebrough, C., 2001. Frustrations of fur-farmed mink. Nature 410, 35-36.

Mathis, A., Schmidt, D.W., Medley, K.A., 2000. The influence of residency status on agonistic behavior of male and female Ozark zigzag salamanders Plethodon angusticlavius. Am. Midl. Nat. 143, 245-249.

Matthews, L.R., Ladewig, J., 1994. Environmental requirements of pigs measured by behavioural demand functions. Anim. Behav. 47, 713-719.

Meyer, S., Weber, J.M., 1996. Ontogeny of dominance in free-living red foxes. Ethology 102, 1008-1019.

Niewold, F.J.J., 1980. Aspects of the social structure of red fox populations: a summary. In: Zimen, E. (Ed.), Biogeographia. The Red Fox, symposium on behaviour and ecology, vol. 18. W. Junk B.V. Publishers, The Hauge, Netherlands, pp. 185-193.

Novak, M.A., Meyer, J.S., Lutz, C., Tiefenbacher, S. Social deprivation and social separation: developmental insights from primatology. In: Mason, G.J., Rushen, J. (Eds.), Stereotypic Animal Behaviour-Fundamentals and Applications to Animal Welfare. CABI, Wallingford, UK, in press.

Patterson-Kane, E.G., Hunt, M., Harper, D., 2002. Rats demand social contact. Anim. Welf. 11, 327-332.

Pedersen, V., Jeppesen, L.L., Jeppesen, N., 2004. Effects of group housing systems on behaviour and production performance in farmed juvenile mink (Mustela vison). Appl. Anim. Behav. Sci. 88, 89-100.

Rushen, J., 1987. A difference in weight reduces fighting when unacquainted newly weaned pigs first meet. Can. J. Anim. Sci. 67, 957-960.

Spruijt, B.M, Van Hooff, J.A.R.A.M., Gispen, W.H., 1992. Ethology and neurobiology of grooming behaviour. Phys. Rev. $72,825-852$.

Sachser, N., Dürschlag, M., Hirzel, D., 1998. Social relationships and the management of stress. Psychoneuroendocrinology 23, 891-904.

SAS, 1990. SAS Users Guide: Statistical Version 6, fourth ed. Statistical Analysis System Institute, Cary, NC, 1686 pp.

Taira, K., Rolls, E.T., 1996. Receiving grooming as a reinforcer for the monkey. Physiol. Behav. 59, 1189-1192.

von Schantz, T., 1981. Female cooperation, male competition, and dispersal in the red fox Vulpes vulpes. OIKOS 37, 6368.

Van Ree, J.M., Niesink, R.J.M., Van Wolfswinkel, L., Ramsey, N.F., Kornet, M.L.M.W., Van Furth, W.R., Vanderschuren, L.J.M.J., Gerrits, M.A.F.M., Van den Berg, C.L., 2000. Endogenous opioids and reward. Eur. J. Pharmacol. 405, 89101.

Warburton, H.J., Mason, G., 2003. Is out of sight out of mind? The effects of resource cuse on motivation in mink Mustela vison. Anim. Behav. 65, 755-762.

Zabel, C.J., Spencer, J.T., 1989. Shift in the red fox, Vulpes vulpes, mating system associated with El Niño in the Bering Sea. Anim. Behav. 38, 830-838.

Zimen, E., 1980. Biogeographia, The Red Fox, vol. 18. W. Junk B.V. Publishers, The Hague, Netherlands. 